\title{
Refighting Pickett's Charge: Mathematical Modeling of the Civil War Battlefield*
}

Michael J. Armstrong, Ph.D.

Associate Professor

Goodman School of Business

Brock University

500 Glenridge Avenue

St. Catharines, ON, L2S 3A1

$9056885550 \times 5323$

michael.armstrong@BrockU.ca
Steven E. Sodergren, Ph.D.

Associate Professor

Department of History

Norwich University

158 Harmon Drive

Northfield, VT 05663

(802) 485-2938

ssodergr@norwich.edu

Direct all correspondence to Michael J. Armstrong, Associate Professor, Goodman School of Business, Brock University, 500 Glenridge Avenue, St. Catharines, ON, L2S 3A1 (Michael.armstrong@ BrockU.ca). The authors will share all data and coding for replication purposes. This research began while the first author was a Fulbright Scholar and Visiting Research Chair in War and Peace Studies at Norwich University. Thanks are due to Fulbright Canada for their funding support. The authors also wish to thank the reviewers at SSQ for their helpful comments.

This is the peer reviewed version of the following article:

Armstrong MJ, Sodergren SE. 2015. "Refighting Pickett's Charge: mathematical modeling of the Civil War battlefield”. Social Science Quarterly 96 \#4 (Dec), 1153-1168, DOI:

$10.1111 /$ ssqu.12178, which has been published in final form at http://onlinelibrary.wiley.com/doi/10.1111/ssqu.12178/abstract.

This article may be used for non-commercial purposes in accordance with Wiley Terms and Conditions for Self-Archiving. 


\title{
Refighting Pickett's Charge:
}

\section{Mathematical Modeling of the Civil War Battlefield}

\begin{abstract}
Objective. We model Pickett's Charge at the Battle of Gettysburg to see whether the Confederates could have achieved victory by committing more infantry, executing a better barrage, or facing a weaker defense. Methods. Our mathematical modeling is based on Lanchester equations, calibrated using historical army strengths. We weight the Union artillery and infantry two different ways using two sources of data, and so have four versions of the model. Results. The models estimate that a successful Confederate charge would have required at least 1 to 3 additional brigades. An improved artillery barrage would have reduced these needs by about 1 brigade. A weaker Union defense could have allowed the charge to succeed as executed. Conclusions. The Confederates plausibly had enough troops to take the Union position and alter the battle's outcome, but likely too few to further exploit such a success.

\section{Introduction}

Pickett's Charge dominates the study of the Civil War battlefield. Thanks to labels such as the "High Water Mark" (Coddington, 1983: xi) and the "Last Invasion" (Guelzo, 2013), historians have identified the events of July 3, 1863 as the climax of the struggle between the Union and Confederates. The engagement's significance carries over to the present day, with Carol Reardon noting the "many different ways July 3 would leave its mark on the nation's historical consciousness" (Reardon, 1997: 202) and thus affect how Americans perceive the Civil War as a whole. The final day at Gettysburg offered the potential for decisiveness on the frustratingly indecisive battlefields of the American Civil War. Not only did General Robert E. Lee's Army of Northern Virginia go down to defeat at the hands of General George Meade's 
Army of the Potomac, but it did so spectacularly with a jarring cannonade and massed assault decided by a bitter hand-to-hand struggle.

Such a climactic moment deserves all of the ink devoted to it, but in a subject rich in counterfactuals few have taken the time to systematically explore the possibility of a Confederate victory and the tremendous impact it could have had on the war's progress. The sheer amount of interest generated by the battle demonstrates how important it was in determining the war's outcome, and thus the possibility of a Confederate victory offers a rich topic for exploration.

The counterfactual debate began almost immediately after the war, as generals (armchair and otherwise) debated the plans, execution and outcome of Pickett's Charge. One of the most incendiary claims came from General James Longstreet, the officer General Lee designated to direct the assault, who would claim after the war that he had told Lee on the morning of July 3 that "there never was a body of fifteen thousand men who could make that attack successfully" (Longstreet, 1956: 343). In his memoirs, Edward Porter Alexander, Longstreet's artillery chief during the battle, seems to agree with his former commander, expressing doubt that the assault would have succeeded even if 5 more brigades had joined in (Gallagher, 1989: 282). Such claims beg analysis, particularly since the Confederates assaulted the Union position with significantly fewer than 15,000 men. Was Longstreet correct in his numerical claim? Were sufficient soldiers available but not utilized? While one may also debate the command styles and tactics employed, a modeling of the numbers and weaponry involved provides a fair starting point for exploring the likelihood of alternative outcomes.

In this paper, we construct simple mathematical models of Pickett's Charge using what are called Lanchester aimed-fire equations. We calibrate the equations using the troop strengths and losses from the historical engagement, so that the models' outputs initially reproduce the 
results of the charge as recorded by historians. We then use the calibrated models to analyze several counterfactual scenarios. In each scenario, we alter the model inputs to represent potential changes in the conduct of the charge, and then examine the impact on the model's outputs. We conclude with a discussion of our findings in the historical context.

\section{Modeling the Battle using Lanchester Equations}

This section describes our mathematical modeling approach. It introduces a class of equations and reviews their use in previous studies. It then details how we use the equations to build a larger multiple-phase model of the charge.

\section{Literature Review}

In this paper we make use of mathematical equations that collectively are known as Lanchester equations or Lanchester (1916) models. Lanchester models are relatively simple aggregated representations of combat, in that they consider only the total number of troops on each side and their relative firepower or "hit rates". In their basic form, the equations do not take into account factors such unit organization, terrain, or maneuver. This simplicity limits their ability to model a battle's details, but makes them practical to apply with relatively basic data.

Lanchester models have been applied to a variety of historical conflicts. For example, Weiss (1966) used them to look for patterns across 64 battles from the American Civil War. Other examples include Iwo Jima (Samz, 1972), Inchon-Seoul (Hartley and Helmbold, 1995), the Ardennes (Hung, Yang, and Deng, 2005), Kursk (Speight, 2011), the Battle of Britain (Johnson and MacKay, 2011), and the air war over North Vietnam (Horwood, MacKay, and Price, 2014). These studies mostly looked at aggregated strengths and casualties rather than those of a single tactical engagement. For example, the analysis in Weiss (1966) of the Battle of Gettysburg used the total casualties across all 3 days of fighting and the total number of soldiers 
in each army. None of these studies involved counterfactual scenarios; instead, they focused on finding the best fitting Lanchester model for each case.

The counterfactual study by Tillman and Engle (1996) is closer in style to our work. Their research examined several scenarios for a potential attack by General Ewell's force against the Union troops defending Culp's Hill on the first day at Gettysburg. Instead of a Lanchester model, they used the U.S. Army's Janus discrete event simulation software to model the battle. Their analysis suggests that without his corps artillery and Johnson's division, Ewell would have been unable to capture and hold the hill. They therefore conclude that Ewell was justified in deciding not to attack it that day.

\section{Main Equations}

In this study we use the "square law" Lanchester model for aimed-fire modern combat. It assumes that the casualties suffered per unit time by each side are proportional to the number of enemy soldiers times their firepower or "kill rate". In this paper, we primarily model the Union and Confederate infantrymen who took part in the engagement. Their respective casualty rates can be expressed by the following pair of differential equations.

$$
d U / d t=-a C_{t} \quad d C / d t=-b U_{t}
$$

$d U / d t$ Change in the number of Union infantrymen per instant of time

$d C / d t$ Change in the number of Confederate infantrymen per instant of time

$t \quad$ Time, where $t=0$ is the start of the skirmish between the two infantry forces

$U_{t} \quad$ Number of Union infantrymen still fighting at time $t$

$C_{t} \quad$ Number of Confederate infantrymen still fighting at time $t$

$b \quad$ Rate at which each Union soldier incapacitates Confederate soldiers

a Rate at which each Confederate soldier incapacitates Union soldiers 
As the battle progresses, each side's fire gradually wears down the enemy force. (If we wanted to model a battle involving a sudden impulse of firepower, such as an airstrike, then we could instead use a salvo combat model, as in Armstrong and Powell, 2005; or Connors, Armstrong, and Bonnett, 2015.) If both sides fight to the death, the loser will be the side that runs out of soldiers first. This attrition can be illustrated graphically by a pair of downward sloping curves, such as in the example shown in Figure 1. Equations 1 and 2 above calculate the slopes of these curves (the casualty rates) at each point in time, while Equations 3 and 4 below calculate the heights of the curves (the surviving forces) at any given time; see, e.g., Taylor (1983) for their derivation. Here, $\exp (x)=e^{x}$ and Euler's constant $e \approx 2.718$.

$$
\begin{aligned}
& C_{t}=1 / 2\left(C_{0}-U_{0}(b / a)^{1 / 2}\right) \exp \left(t(a b)^{1 / 2}\right)+1 / 2\left(C_{0}+U_{0}(b / a)^{1 / 2}\right) \exp \left(-t(a b)^{1 / 2}\right) \\
& U_{t}=1 / 2\left(U_{0}-C_{0}(a / b)^{1 / 2}\right) \exp \left(t(a b)^{1 / 2}\right)+1 / 2\left(U_{0}+C_{0}(a / b)^{1 / 2}\right) \exp \left(-t(a b)^{1 / 2}\right)
\end{aligned}
$$

The winner can be determined by comparing the respective products of the kill rates and the force strengths squared. If $a C_{0}^{2}>b U_{0}^{2}$, then the Union force will be eliminated and the Confederates will win. If $a C_{0}^{2}<b U_{0}^{2}$, then the Confederate force will be eliminated and the Union will win. If $a C_{0}^{2}=b U_{0}^{2}$, then both sides will be eliminated and the battle will end in a tie. Of course, typically the side that is losing will withdraw before being completely eliminated. The following equations estimate the survivors on one side at the point in the battle where the opposing side has reached some chosen strength level $C_{L}$ or $U_{L}$.

$$
C_{L}=\left(C_{0}^{2}-(b / a) U_{0}^{2}+(b / a) U_{L}^{2}\right)^{1 / 2} \quad U_{L}=\left(U_{0}^{2}-(a / b) C_{0}^{2}+(a / b) C_{L}^{2}\right)^{1 / 2}
$$

\section{Modeling an Assault on a Defensive Position}

The defense appeared to reign supreme during the Civil War, with massed assaults against prepared positions going down to defeat at such well known battlefields as Fredericksburg and Malvern Hill. McWhiney and Jamieson extensively praise defensive 
methods during the war, declaring that "The South simply bled itself to death in the first three years of the war by taking the tactical offensive in nearly 70 percent of the major actions" (1982: 7). They repeatedly emphasize the power of rifles and field entrenchments in enhancing the defensive capabilities of Civil War armies (1982: 58, 73). Griffith also argues for defensive supremacy during the war. While downplaying the power of the rifle, Griffith identifies the psychological power that entrenched positions gave the defender over the attacker, and noted that Civil War artillery amplified the defense "beyond the statistical reckoning" (1989: 127-135, 171).

However, adopting a defensive posture did not guarantee victory. Massed assaults could and did capture fortified or elevated positions, perhaps most famously in the Union victory at Missionary Ridge in November 1863. Thus, there was no reason to assume then or now that Pickett's Charge was doomed to fail. While the Union position was well-prepared, it was not entrenched, and the Confederate advance faced only a gradual slope. Coddington notes the potential for a successful massed assault against the Union center. Cemetery Ridge offered little in the way of a wood line to cover its defenders, and the route of advance had few natural obstacles to break up assault formations (1968: 459). Ultimately, Coddington concludes that the position “was difficult but not impossible to take.” (1968: 463).

To model the Confederate assault, we follow the advice of Weiss (1966). He argued that an assault against a defensive position should be modeled in phases. Initially, the attacker advances while taking casualties from defensive fire; the defender's losses during this phase are negligible. After the attacker has closed the distance, however, it begins to engage the defender, so that both sides take casualties during that phase. 
Ideally, we would like to represent Pickett's Charge with a detailed multi-phase model of progressively heavier fire. After an initial artillery barrage phase where the cannons of both sides fire, the Confederate infantry would advance. The Union forces would open up first with long range cannon fire (shot and shell), followed by short range cannon fire (case and canister), long range rifle fire, short range musket fire, and finally hand-to-hand combat. To calibrate such a complex model, however, would require detailed data as to the number of Confederate casualties that were due to each type of fire. Such data are simply unavailable for this battle.

Instead, we model the engagement with three phases. Phase I represents the preliminary barrage by the Confederate artillery, and the corresponding return fire from the Union artillery. We model this barrage by multiplying the number of cannon on each side by a firepower coefficient that represents the average number of casualties inflicted per gun during the barrage. As was largely the case with the actual barrage, Confederate cannons are assumed to hit both Union cannons and infantry, while Union cannons hit only Confederate infantry.

Phase II represents the Confederate infantry advancing across the field while the surviving Union cannons fire at them. We again calculate the effect of Union fire by multiplying the number of guns by the average casualties per gun. The Union infantry do not fire during this phase, nor do any of the Confederate forces.

Phase III represents the skirmish between Confederate and Union infantry that starts once they come within rifle range of each other. This is where we make use of Lanchester equations to model the surviving infantry firing simultaneously at each other. The "starting" strength of each side in Phase III is the number of infantrymen that survived the barrage (Phase I) and the advance (Phase II). As an approximation, we assume that neither side's artillery fires during this 
stage. This is a reasonable assumption given the desire by both Union and Confederate artillery to avoid firing at their own men.

It is not known for certain how many Confederate casualties occurred during each phase. It is clear that Union artillery caused a large proportion of Confederate infantry casualties. Sears (2003: 425) notes that in the $11^{\text {th }}$ Mississippi, between $1 / 3$ and $1 / 2$ of the total casualties were due to Union artillery fire. Griffith claims that artillery inflicted $50 \%$ of the casualties for the attackers at Fredericksburg and Malvern Hill, which were similar massed assaults against welldefended positions (1989: 170). To reflect this range of uncertainty, we try 2 different settings for our model. In one, the Union artillery produces $50 \%$ of the casualties suffered by the Confederate infantry during their historical advance (i.e., during Phases II and III). In the other, the artillery produces only $25 \%$ of these casualties.

\section{Historical Data}

In addition to allocating casualties two different ways between artillery and musket fire, we also use data on troop strengths and losses from two different sources: Sears (2003) and Stewart (1959). This redundancy provides some assurance that our results are not merely an artifact of one particular choice of numbers. We are interested both in the forces that actually took part in the engagement, as well as those that plausibly could have participated.

\section{Troops Actually Committed}

After two days of pitched battle near Gettysburg, the Union lines had held and Lee was searching for an opportunity to break his enemy's defenses. He settled upon the approximate middle of the Union position, located on a low rise called Cemetery Ridge. A massive cannonade would precede an infantry assault against this position. Sears states Lee massed 163 cannon against the Union center with 9 more in reserve (2003: 380-3) while Stewart counts 143 
guns with 7 in reserve (1959: 114). In the Union lines, Sears places 133 guns initially; 18 of these were knocked-out or withdrawn during the barrage, while 6 replacements were brought up from the reserve after the barrage ended $(406,414,433)$. Stewart's numbers for the Union are lower, with only 103 guns originally on line, 20 lost, and 10 replacements brought forward (1959: 114, 160).

Pickett's division, fresh to the battlefield, would be the right wing of the Confederate assault, while Henry Heth's division (then commanded by Johnston Pettigrew) and elements of Isaac Trimble's division would form the left. All told, 9 infantry brigades would participate in the assault. Estimates of the actual number of soldiers vary significantly from source to source, with 10500 cited by Stewart (1959: 172-3) and 13030 by Sears (2003: 392). By the end of the day, Stewart identified 6467 Confederate casualties (killed, wounded and missing), of which approximately 350 were inflicted by Union artillery fire prior to the assault; this left 4033 effectives (1959: 263, 161). Sears identifies 6600 total casualties; subtracting the 360 suffered by Lang \& Wilcox (two support units addressed below) leaves 6240 losses from the 9-brigade main force. Sears does not give an estimate for the pre-assault casualties inflicted by Union artillery, so applying Stewart's 350 number to Sears' figures, we find 5890 casualties occurred during the charge leaving 6790 effectives from the original force. (2003: 455, 467-9).

Defending the ridgeline from the impending assault was a mixture of fresh and blooded Union troops. In the center was John Gibbon's division of three brigades from Winfield Hancock's Second Corps, supported by two brigades and a regiment from Alexander Hays' division. Additional elements from Abner Doubleday's division of First Corps were in support, including a strong contingent of Vermont troops. Thus the equivalent of 6 to 7 Union brigades would attempt to halt the Confederate attack, with estimated numbers of 5750 from Stewart 
(1959: 173-4) and 7980 from Sears (2003: 410, 415). Sears identifies 2300 casualties among the Union forces, including approximately 175 due to the Confederate bombardment; 5680 remained (2003: 404, 468-9). Stewart calculates only 1300 Union casualties, including 200 during the preliminary barrage; 4250 survived uninjured $(1959: 262,161)$.

\section{Additional Confederate Troops Available}

The Confederate assault did not occur in a vacuum; additional units stood by ready, though many had seen high casualties in the previous days of the battle and thus were not assigned to the initial attack. The brigades of Cadmus Wilcox and David Lang were in support on the right and actually advanced later to reinforce the assault, bringing an additional 14001600 men towards the Union line (Stewart, 1959: 172-3 \& Sears, 2003: 454). They went in too late to properly support the assault, however, and suffered 360 casualties from Union artillery fire before retreating (Sears, 2003: 454-55).

According to Sears, three additional brigades from Anderson's division under Wright, Posey and Mahone were "loosely designated" as support on the left for the attack, but never engaged. They contained approximately 3350 men (Sears, 2003: 392). Stewart notes that at least Wright's brigade was briefly moved forward, but Longstreet recalled it to defend against a potential counterattack (1959: 237). The remainder of Longstreet's corps also stood in the area, and thus Coddington notes that Lee "anticipated throwing another 10,000 or so infantry into the breach he expected to be made by the assaulting column" (Coddington, 1983: 462).

\section{Calibrating the Model}

The first step in the analysis is to use the historical data described above to "calibrate" the models to reproduce the results of the actual battle. That is, we use both sides' known starting and ending strengths to calculate the equation coefficients. The following paragraphs describe 
this calibration procedure for the model version that uses data from Sears (2003) in conjunction with the approximation that $50 \%$ of Confederate losses were due to artillery (hereafter, the "Sears 50\%" model). The corresponding calculations for the other 3 model versions are given in the Appendix.

For the Phase I preparatory barrage, we need to find the firepower or hit rate coefficients for both sides' artillery. 163 Confederate cannon fired at the Union lines; they knocked-out 18 guns and inflicted 175 infantry casualties. Thus we set their firepower coefficients at 18/163= 0.1104 guns/gun against the artillery and $175 / 163=1.0736$ soldiers/gun against the infantry. Meanwhile, the 133 Union guns caused 350 Confederate casualties, so their Phase I firepower coefficient is $350 / 133=2.6316$ soldiers/gun .

For the Phase II advance, the Union artillery has $133-18+6=121$ guns, while the Confederates begin with $13030-350=12680$ infantry. We need the model to produce 5890 casualties during Phases II and III combined. To get $50 \%$ of that from artillery in Phase II, i.e., $5890 / 2=2945$, their firepower coefficient needs to be $2945 / 121=24.3388$ soldiers/gun.

For the Phase III infantry skirmish, we need to work out the firepower coefficients $a$ and $b$ for the Lanchester equations. The Union begins with $7980-175=7805$ infantry and ends at 5680. The Confederates begin with $12680-2945=9735$ soldiers and end at 6790 after they break off the engagement. Since only the ratio of the coefficients matters, we fix the Confederate value $a=1$, and then solve for the Union value of $b$ using Equation 4. That is, to get $5680=\left(7805^{2}-(1 / b) 9735^{2}+(1 / b) 6790^{2}\right)^{1 / 2}$, we must have $b=1.6980$. Roughly speaking, this means that on average each Union infantryman was knocking out targets 1.7 times faster than each Confederate infantryman. This difference is not surprising: the Union infantry were mostly standing and shooting, while the Confederates spent much of their time marching. 
These coefficients are listed in the first column of Table 1. The remaining columns give the coefficients for the other 3 versions of our model: Sears' data with $25 \%$ artillery-caused losses, Stewart's data with $50 \%$ artillery-caused losses, and Stewart's data with $25 \%$ artillerycaused losses. The appendix describes their calculation.

[Insert Table 1 about here]

\section{Counterfactual Analysis}

We now have 4 versions of a model that can be used to explore potential changes in the conduct of the charge and the result of the overall battle. For ease of use, these are implemented as Excel spreadsheets; a copy of the Excel file is available upon request from the authors.

\section{Scenario 1: Prolonged Skirmishing}

In the actual battle, the Confederate infantry withdrew after suffering heavy losses. But what if they and the Union soldiers had kept on skirmishing in a "fight to the death"? Equations 3 and 4 can be used to calculate the continued attrition of both sides. The results for the Sears 50\% model are illustrated in Figure 1. The solid line represents the Confederate infantry while the dashed line represents the Union infantry, from the start of the Phase II advance onward. The Confederates run out of soldiers first, and so lose an extra 6790 men, whereas the Union losses (calculated using Equation 6) only increase by 3419.

[Insert Figure 1 about here]

Calculations with the other 3 model versions (shown in the Appendix) likewise have the Confederates being eliminated first and with heavier incremental losses than their Union opponents. This indicates the Confederates were justified in pulling back when they did.

Suppose now that the Confederates had sent more infantry in the initial assault. How many would have been needed to just barely achieve a "tie"; that is, to cause the Union and 
Confederate forces to both run out of infantry at the same time? As noted earlier, the Lanchester model will predict such a result whenever $a C_{0}^{2}=b U_{0}^{2}$. In the Sears $50 \%$ model, the Confederates will achieve this if they start the infantry skirmish with $C_{0}=\left(1.6980(7805)^{2}\right)^{1 / 2}=$ 10171 soldiers. To get that many into the Phase III skirmish, they would need another 2945 to cover their losses due to Union artillery during the Phase II advance, plus 350 more for their losses during the Phase I artillery barrage. This gives a total requirement of 13466 soldiers at the beginning of the barrage, or 436 more than they actually sent. Anything less would leave some surviving Union troops on the ridge; anything greater would give the Confederates possession of the ridge, and also reduce their casualties.

The first row of Table 2 summarizes the estimated thresholds from all 4 model versions. These range from 436 to 3227 extra soldiers, or roughly $1 / 2$ to 3 extra brigades.

[Insert Table 2 about here]

An alternative way to express the results is via the ratios of Confederate to Union infantry. In the actual charge, Sears (2003) estimates the Confederates started with 13030 infantry versus the Union's 7980, giving a ratio of 1.63-to-1. Stewart's (1959) estimates of 10500 and 5750 put the ratio at 1.83-to1. By comparison, our models estimate the Confederates would have needed to outnumber the Union force by somewhere between 1.69-to-1 and 2.39-to1 just to break even. Roughly speaking, this suggests that a ratio around 2-to-1 would have achieved mutual elimination, while one closer to 3-to-1 would have allowed the Confederates to readily capture the ridge. (A 3-to-1 ratio has sometimes been suggested as a rule of thumb for a successful attack. See, e.g., the review in Kress and Talmor, 1999).

It would certainly have been possible, though not necessarily easy, for the Confederates to have committed these extra soldiers. For example, if the two brigades under Wilcox and Lang 
had been part of the initial advance, instead of being sent in later, they would have contributed another 1600 men to the skirmish (Sears, 2003: 454). The three remaining brigades from Anderson's division, which were "loosely designated" to provide support, could have added another 3350 (Sears, 2003: 392).

Figure 2 shows the same situation as Figure 1, but with 1600 extra men in the initial Confederate force. With this addition, the Union runs out of infantry first. The Confederates capture the position and have 5003 men left. In this example, a relatively modest change in the starting forces produces a large change in the assault's outcome.

[Insert Figure 2 about here]

\section{Scenario 2: Improved Confederate Barrage}

Alexander had originally intended to fire a longer initial barrage, and also make use of several guns from the army's artillery reserve. Unfortunately, General Pendleton, the Confederate Chief of Artillery, repositioned both the reserve and the ammunition train during the barrage (Sears, 2003: 407), making them unavailable. In his memoirs, Alexander remembers Longstreet's dismay when told that the barrage would be shorter than planned, even going so far as to suggest that it was doomed to fail as a result (Gallagher, 1989: 261).

In this subsection we suppose this artillery mix-up had been avoided. Alexander's artillery crews could have reloaded their caissons with ammunition, and presumably would have fired twice as many rounds as they actually did. They would also have added the reserve guns to the firing line. Would this enhanced barrage by itself have allowed a Confederate win? If not, to what extent would it have reduced the threshold of forces needed?

This counterfactual is quite plausible; it only requires that the Confederate officers had better coordinated their plans. Coordination, or the lack of it, is a common theme in discussions 
of Pickett's Charge. For example, Piston (1994) cites the lack of coordination and direction from Lee as being a flaw in the planning and execution of the July 3 assaults, and Alexander cites faulty staff work and communication as contributing to the attack's failure (1989: 283).

To model this scenario, we double the firepower coefficients of the Confederate artillery and add the extra guns. With the Sears 50\% model, the cannons increase to $163+9=172$. Their firepower coefficients become 0.2208 guns/gun against the artillery and 2.1472 soldiers/gun against the infantry. The other parameters remain unchanged.

Not surprisingly, Union losses during the initial barrage (Phase I) more than double in this scenario. The Union loses 38 guns instead of 18, and 369 infantry instead of 175 . Because there are fewer Union cannons firing during the advance (Phase II), the Confederates lose 2458 infantry instead of 2945. They enter the skirmish (Phase III) with 10222 infantry instead of 9735, and face 7611 Union infantry instead of 7805. The Confederates consequently gain a victory and have 2476 survivors, while the Union infantry is eliminated.

As before, we can calculate the number of Confederate soldiers needed for mutual elimination. The new value is $\left(1.6980(7611)^{2}\right)^{1 / 2}+2458+350=12728$ infantry, or 302 less than they actually committed. The corresponding thresholds for the other 3 models are shown in the second row of Table 2. In those cases, the Confederates still would have needed extra infantry, but many fewer than with the original barrage. This suggests that Lee and Longstreet were justified in thinking that a proper preparatory barrage was important for Confederate success, although it probably would not have been sufficient by itself.

\section{Scenario 3: Lee's Idealized Barrage}

This scenario takes the Confederate barrage a step further by assuming it achieves Lee's vision of completely neutralizing the artillery in the Union center. As Sears notes, "The 
bombardment was the critical element of the plan. Lee ... intended this unprecedented volume of gunnery to pulverize the defending Federal batteries and overwhelm and demoralize the defending Federal infantry" (Sears, 2003: 377). We do not believe this outcome was very plausible, and the postwar pessimism of Longstreet and Alexander appears to confirm this. However, we model it so as to evaluate Lee's plans; if the artillery barrage had been as effective as he had envisioned, would the infantry charge have been as successful as he had hoped?

For this scenario, we first carry out the improved barrage Scenario 2, giving the Confederate artillery its reserve guns and doubled firepower. We then delete any guns in the Union center that either survive the barrage or were sent there as reinforcements. This leaves just 49 guns according to Sears $(2003: 373-375,414,421)$, or 39 according to Stewart (1959: 72 74) on the Union flanks on Cemetery Hill and Little Round Top.

With this change in the Sears 50\% model, the Confederate casualties during the advance decrease to $49 \times 24.3388=1193$. They now need only $\left(1.6980(7611)^{2}\right)^{1 / 2}+1193+350=11461$ infantry to obtain a tie, which is 1569 less than they actually committed.

The results for all 4 models are shown in the third row of numbers in Table 2. Two of them estimate the Confederates would have had enough troops in the charge, while the other two indicate they would have needed more. This suggests that, despite Lee's expectations, even a very powerful barrage might not have made the rest of the charge a success.

\section{Scenario 4: Weaker Defenses}

The outcome of the charge was determined as much by the actions of the Union army as by those of the Confederate one. At Gettysburg, General Meade concentrated on building a strong defensive position, and as units arrived he directed them to whatever position seemed most threatened. This sometimes meant splitting up larger formations. For example, although 
Second Corps was responsible for the Union center, it was reinforced with units from other formations, including Stannard's Vermont brigade from First Corps (Sears, 2003: 414). This strengthened the Union defenses, but arguably left the army less able to shift over to the offense because there was no formed corps in reserve ready to counterattack. Meade would receive criticism following the war for this defensive attitude, particularly from Dan Sickles; he argued that Meade had been looking for an excuse to retreat from Gettysburg (Sauers, 1989).

But what if Meade had been less cautious? He could have held back more units in an organized reserve, ready to counterattack, rather than deploying them piecemeal to shore up his lines. In the Union center, this likely would have meant fewer units attached to Second Corps, and hence less infantry in position to defend against Pickett's Charge. To represent this possibility, we remove the Vermont brigade and its 1400 (Stewart, 1959: 173) or 1950 (Busey and Martin, 1994: 29) infantry from the Union defense, under the assumption that it had been kept with its parent corps. We leave the other factors unchanged from the historical base case; in particular, the initial artillery barrage functions as in Scenario 1.

In the Sears 50\% model, Phases I and II proceed as in the historical case. In Phase III, the Union starts with only $7805-1950=5855$ infantry, and so the Confederates now need $\left(1.6980(7805-1950)^{2}\right)^{1 / 2}+2945+350=10925$ infantry, or 2105 less than what they actually sent. In this case, the Confederate force would have been sufficient to take the position.

The results for all 4 models are summarized in the fourth row of Table 2. The thresholds are much lower in all 4 cases, and 3 of them estimate the Confederate charge would have been successful without reinforcements. This suggests that Meade was justified in reinforcing his lines as he did, and that the Vermont regiments played a significant role in repelling the assault.

\section{Scenario 5: Improved Barrage and Weakened Defense}


Our last scenario examines the outcome of having both an improved Confederate barrage and a weakened Union defense. For the Confederates, we increase the number and firepower of cannons, as in Scenario 2. For the Union, we reduce the number of infantry, as in Scenario 4.

In the Sears 50\% model, the Confederates have 172 cannon with coefficients of 0.2208 guns/gun and 2.1472 soldiers/gun. The Union starts with $7980-1950=6030$ infantry, and loses 38 guns and 369 infantry during Phase I. The Confederates lose 2458 infantry during Phase II, and face just $6030-369=5661$ Union soldiers in Phase III. The Confederates now need only $\left(1.6980(7980-1950-369)^{2}\right)^{1 / 2}+2458+350=10185$ infantry, or 2845 less than actually sent.

The other models' results are shown at the bottom of Table 2. All of the thresholds are lower, indicating the charge would have succeeded without reinforcements.

\section{Discussion and Conclusions}

Our modeling results provide plausible evidence that the Confederates could have captured Cemetery Ridge if they had committed more of their available infantry to the initial charge. We estimate that they would have needed between 436 and 3227 more men in the main charge to eliminate the Union defenders; a better coordinated barrage would have significantly reduced those needs. Such additions were certainly within their reach, given the 1400 to 1600 men available in the brigades of Wilcox and Lang, and the further 3350 men standing by under Wright, Posey, and Mahone. Our results therefore support Longstreet's original estimate of needing more than 15,000 men, but not his later claim that "thirty thousand men was the minimum of force necessary" (Longstreet, 1960: 386).

Fewer reinforcements would have been needed if the barrage had been as destructive as Lee had envisioned it, or if Meade had not reinforced his center with extra units. In both cases, 
the charge could well have succeeded even without any added men. Of course, neither of those scenarios was within the control of the Confederate commanders.

When discussing these strength thresholds, it is important to keep in mind that they are bare minimums. If the Confederates had attacked with, say, just 1 more soldier than required by a threshold in Table 2, then the model estimates they would have won the position, but with just that 1 soldier surviving to occupy it. More realistically, they would have needed to send at least 1 brigade more than the minimum to occupy the position, plus additional brigades to hold off counterattacks and/or exploit the success by attacking the Union left or right.

Longstreet's "15,000 men" claim after the war strongly implied that he had wanted more troops in the initial attack, and other Confederate commanders also suggested then and later that the men designated for support should have been thrown into the assault. For example, Alexander noted a rumor that Lee "intended to march every man he had upon the cemetery hill that day." (Gallagher, 1989: 255). Similarly, A.P. Hill spoke to Lee that morning and urged a massed assault in keeping with Napoleon's belief that "In the decisive attack the last man and the last horse should be thrown in.” (Stewart, 1959: 90).

However, just because the Confederates had more forces available does not mean that it would have been wise to commit them. Lee and Longstreet also needed to anticipate potential Union responses. A larger initial force may have broken through the Union lines, but the remaining Confederates may have been insufficient to hold the position. As Coddington notes, "If Lee had employed a much larger number of troops in the attacking force, he would have risked the security of his whole army by exposing it to enemy counterthrusts in case his own assault failed.” (1968: 463). Stewart sees Longstreet's orders to hold back the brigades of Wright, Posey and Mahone as justified along similar lines (1959: 237). Finally, Lee did not 
merely want to break the Union lines; he sought to completely unhinge them. Adding more men to the initial assault would have diminished his ability to exploit any breaches. Thus, it seems that while Lee could have captured The Angle via a better barrage and a larger charge, adding more men to the initial assault would have added significant risk to his ability to exploit a breakthrough and achieve the larger victory he was seeking.

Would the risk have been worth it? The Confederates' defeat at Gettysburg, coupled with their nearly simultaneous surrender at Vicksburg, dealt a major blow to the Southern war effort. Lee remained on the strategic defensive for the remainder of the war, and Confederate forces in the eastern theater of operations never again undertook a substantial foray into the northern states. Their forces out west faced similar limitations following Vicksburg. It is fair to say that even a minor tactical victory at Gettysburg, which a Confederate breakthrough at Cemetery Ridge could have provided, would have altered the future tempo of operations in the east. Instead of Lee having to respond to Union operations, he could have retained the initiative; and Lee was most dangerous when he controlled the battlefield. While all of this entails a great deal of speculation, the counterfactual scenarios presented here offer at least a first step towards exploring alternate outcomes to the largest battle of the American Civil War. 


\section{REFERENCES}

Armstrong, Michael J, and Michael B Powell. 2005. "A salvo combat analysis of the Battle of the Coral Sea." Military Operations Research 10 \#4: 27-38.

Busey, John W. and David G. Martin. 1994. Regimental Strengths and Losses at Gettysburg. Hightstown, NJ: Longstreet House.

Coddington, Edwin B. 1968. The Gettysburg Campaign: A Study in Command. New York: Scribners.

Connors D, Armstrong MJ, and Bonnett J. 2015. "A counterfactual study of the Charge of the Light Brigade". Forthcoming in Historical Methods.

Gallagher, Gary, ed. 1989. Fighting for the Confederacy: The Personal Recollections of General Edward Porter Alexander. Chapel Hill: University of North Carolina Press. Griffith, Paddy. 1989. Battle Tactics of the Civil War. New Haven: Yale University Press. Guelzo, Allen C. 2013. Gettysburg: The Last Invasion. New York: Alfred A. Knopf. Hartley, DS, and RL Helmbold. 1995. "Validating Lanchester's square law and other attrition models." Naval Research Logistics 42 \#4: 609-633

Horwood I, MacKay N, and Price C. 2014. "Concentration and asymmetry in air combat: lessons for the defensive employment of air power." To appear in RAF Air Power Review. Hung, CY, GK Yang, and PS Deng. 2005. "Fitting Lanchester's square law to the Ardennes Campaign.” Journal of the Operational Research Society 56 \#8: 942-946.

Johnson, IR, and NJ MacKay. 2011. "Lanchester Models and the Battle of Britain.” Naval Research Logistics 58 \#3: 210-222.

Kress M, and Talmor I. 1999. "A new look at the 3:1 rule of combat through Markov stochastic Lanchester models". Journal of the Operational Research Society 50, 733-744. 
Lanchester, FW. 1916. Aircraft in Warfare: The Dawn of the Fourth Arm. London: Constable. McWhiney, Grady and Perry Jamieson. 1982. Attack and Die: Civil War Military Tactics and the Southern Heritage. Tuscaloosa: University of Alabama Press.

Piston, William Garrett. "Cross Purposes: Longstreet, Lee, and Confederate Attack Plans for July 3 at Gettysburg." 1994. The Third Day at Gettysburg and Beyond. Chapel Hill: University of North Carolina Press.

Reardon, Carol. 1997. Pickett's Charge in History and Memory. Chapel Hill: University of North Carolina Press.

Samz, RW. 1972. "Some comments on Engel's 'A verification of Lanchester's Law”.” Operations Research 20: 49-52.

Sauers, Richard A. 1989. A Caspian Sea of Ink: The Meade-Sickles Controversy. Baltimore: Butternut \& Blue.

Sears, Stephen W. 2003. Gettysburg. Boston: Houghton Mifflin Company.

Speight, LR. 2011. "Within-Campaign Analysis: A Statistical Evaluation of the Battle of Kursk." Military Operations Research 16 \#2.

Stewart, George. 1959. Pickett's Charge: A Microhistory of the Final Attack at Gettysburg, July 3, 1863. Boston: Houghton Mifflin.

Taylor, James G. 1983. Lanchester Models of Warfare. Arlington: Operations Research Society of America.

Tillman, ME, and CB Engle. 1996. "A historical reenactment of the battle of Gettysburg on Janus (Army).” Mathematical and Computer Modelling 23 \#1-2: 1-8.

Weiss, Herbert K. 1966. "Combat models and historical data: The U.S. Civil War.” Operations Research 14 \#5: 759-790. 


\section{Table 1.}

Summary of model coefficients.

\begin{tabular}{lcccc}
\hline Phase \& Coefficient & Sears 50\% & Sears 25\% & Stewart 50\% & Stewart 25\% \\
\hline I. Confederate gun v. gun & 0.1104 & 0.1104 & 0.1399 & 0.1399 \\
I. Confederate gun v. infantry & 1.0736 & 1.0736 & 1.3986 & 1.3986 \\
I. Union gun v. infantry & 2.6316 & 2.6316 & 3.3981 & 3.3981 \\
II. Union gun v. infantry & 24.3388 & 12.1735 & 32.8817 & 16.4409 \\
III. Confederate infantry v. infantry & 1.0000 & 1.0000 & 1.0000 & 1.0000 \\
III. Union infantry v. infantry & 1.6980 & 2.7737 & 2.6714 & 4.5570 \\
\hline
\end{tabular}

Table 2.

Additional soldiers needed by the Confederates to eliminate the Union defenders in each scenario and model version. (Parentheses) indicate they have a surplus.

\begin{tabular}{lcccc}
\hline Scenario & Sears 50\% & Sears 25\% & Stewart 50\% & Stewart 25\% \\
\hline 1. Historical & 436 & 1792 & 1980 & 3227 \\
2. Improved barrage & $(302)$ & 1227 & 898 & 2397 \\
3. Lee's vision & $(1569)$ & 592 & $(156)$ & 1871 \\
4. Weaker defense & $(2105)$ & $(1435)$ & $(309)$ & 239 \\
5. Barrage and defense & $(2845)$ & $(2023)$ & $(1390)$ & $(592)$
\end{tabular}


Figure 1. Infantry strengths using the Sears $50 \%$ model with historical forces.

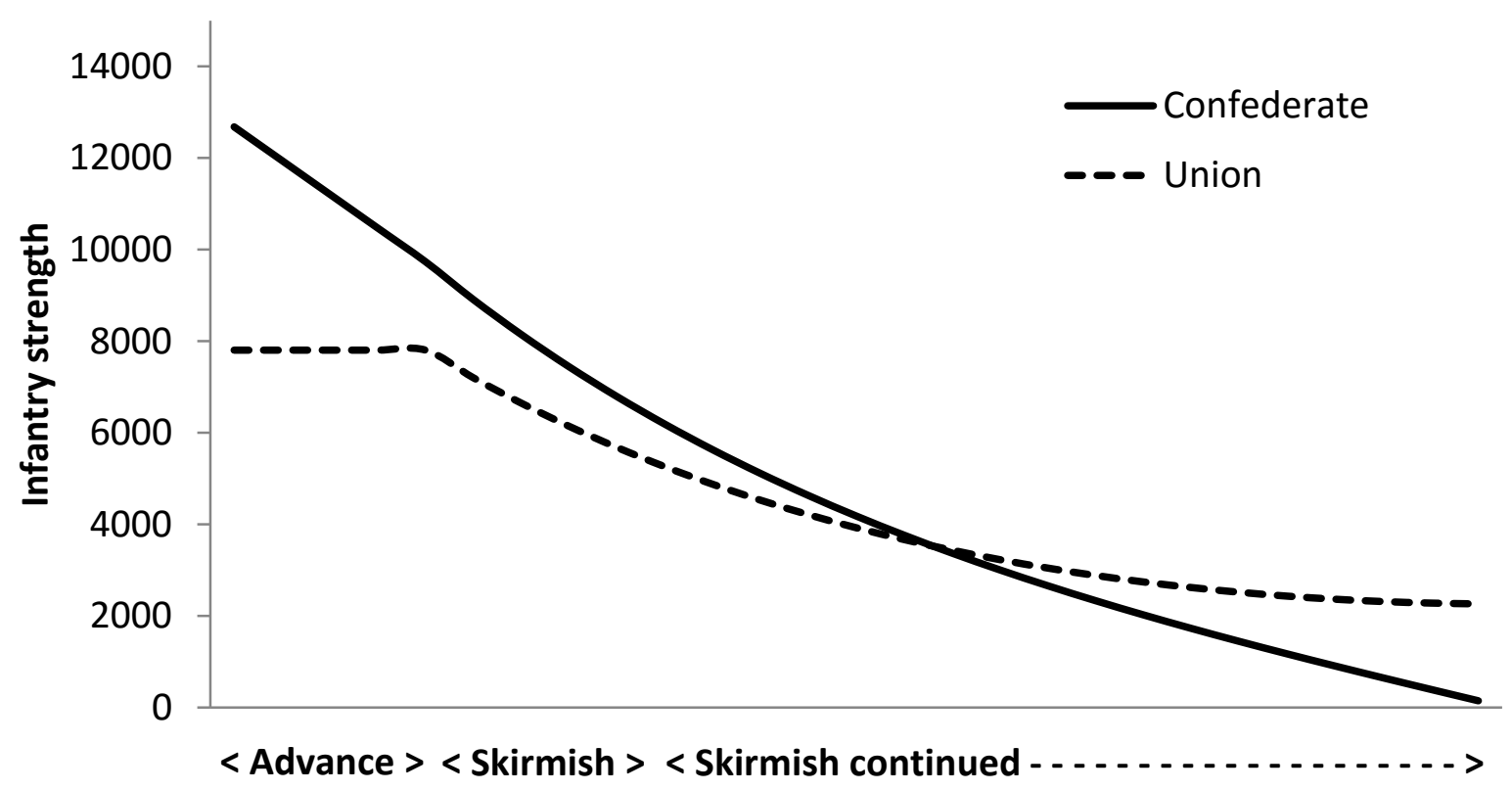

Figure 2. Infantry strengths using the Sears 50\% model with 1600 extra Confederates.

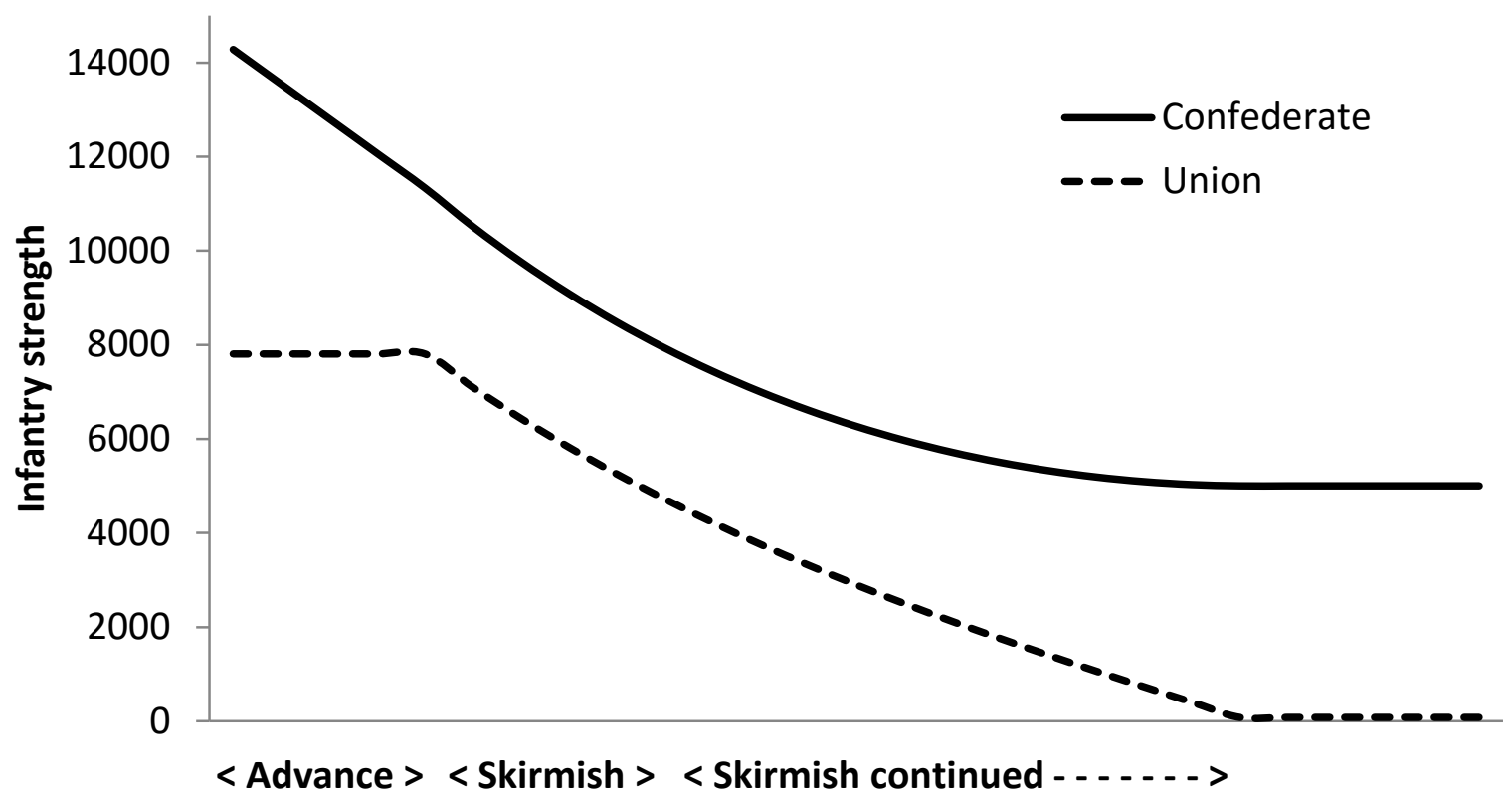




\section{Appendix: Additional Calculations}

The main text describes calculations for the "Sears 50\%" model; i.e., the model version that uses data from Sears (2003) and assumes that 50\% of Confederate losses during Phases II and III are from artillery fire. This appendix gives the calculations for the other 3 versions.

\section{Calibration}

In the Sears $25 \%$ model the Phase I coefficients are the same as in the Sears $50 \%$ model. For Phases II and III, we need Confederate losses of 5890/4 = 1473 to come from Union artillery fire. Thus the Union Phase II artillery coefficient must be $1473 / 121=12.1735$ soldiers/gun. The Confederates begin Phase III with $12680-1473=11207$ soldiers and end at 6790, while the Union begins with 7805 and ends at 5680 . The formula $5680=\left(7805^{2}-(1 / b) 11207^{2}+\right.$ $\left.(1 / b) 6790^{2}\right)^{1 / 2}$ thus implies a Union infantry firepower coefficient of $b=2.7737$.

Using Stewart's data, in Phase I the 143 Confederate guns knock out 20 Union guns and 200 infantry, making their coefficients $20 / 143=0.1399$ guns/gun and 200/143 $=1.3986$ soldiers/gun. The Union's 103 guns inflict 350 casualties, thus 350/103 = 3.3981 soldiers/gun.

For Phase II, the Union has $103-20+10=93$ guns, while the Confederates start with $10500-350=10150$ infantry. For the Stewart $25 \%$ model, $6117 / 4 \approx 1529$ of subsequent casualties are from artillery fire, giving $1529 / 93=16.4409$ soldiers/gun. For the Stewart 50\% model, $6117 / 2 \approx 3058$ Confederates are casualties, giving 3058/93 $=32.8817$ soldiers $/$ gun .

For Phase III, the Union begins with $5750-200=5550$ infantry and ends at 4250 . In the Stewart $25 \%$ model, the Confederates begin at $10500-350-1529=8621$ men and end with 4033. So $4250=\left(5550^{2}-(1 / b) 8621^{2}+(1 / b) 4033^{2}\right)^{1 / 2}$ implies $b=4.5570$. In the Stewart $50 \%$ model, the Confederates begin at $10150-3058=7092$. Thus $4250=\left(5550^{2}-(1 / b) 7092^{2}+\right.$ $\left.(1 / b) 4033^{2}\right)^{1 / 2}$ implies $b=2.6714$. 


\section{Counterfactual Analysis}

\section{Scenario 1: Prolonged Skirmishing}

In a fight to the death, all the models predict elimination of the Confederate infantry. The Sears 25\% model estimates the increase in Union casualties at 1725 men. The Stewart 50\% model puts the extra Union losses at 790, while the Stewart 25\% model estimates 433 .

The Sears $25 \%$ model puts the number of Confederate infantry needed for a tie at $\left(2.7737(7805)^{2}\right)^{1 / 2}+1473+350=14822$, or 1792 more than actually sent. The Stewart 50\% model suggests $\left(2.6714(5550)^{2}\right)^{1 / 2}+3058+350=12480$ total, or 1980 extra. The Stewart $25 \%$ model suggests $\left(4.5570(5550)^{2}\right)^{1 / 2}+1529+350=13727$ total, or 3227 extra.

\section{Scenario 2: Improved Confederate Barrage}

In Phase I with the Sears 25\% model, the Union initially loses 38 guns and 369 infantry. During Phase II the Confederates lose 1231 infantry. To draw they need $\left(2.7737(7611)^{2}\right)^{1 / 2}+$ $1231+350=14257$ infantry, or 1227 more than they sent.

Using Stewart's data, the Confederate cannons increase to 150 while their coefficients double to 0.2798 guns/gun and 2.7972 soldiers/gun. During Phase I the Union loses 42 guns and 420 infantry. During Phase II the Confederates lose 2336 in the Stewart 50\% model and 1168 in the Stewart 25\% model. The Stewart 50\% model estimates the Confederates would need $\left(2.6714(5330)^{2}\right)^{1 / 2}+2336+350=11398$ soldiers, or 898 extra. The Stewart $25 \%$ model puts the number at $\left(4.5570(5330)^{2}\right)^{1 / 2}+1168+350=12897$, or 2397 extra.

\section{Scenario 3: Lee's Idealized Barrage}

In the Sears $25 \%$ model the Confederate casualties during the advance drop to $49 \mathrm{x}$ 12.1735 $=597$. They therefore need to send $\left(2.7737(7611)^{2}\right)^{1 / 2}+597+350=13623$ infantry, or 592 extra. In the Stewart 50\% model, the casualties while advancing are $39 \times 32.8817=1282$. 
The threshold becomes $\left(2.6714(5330)^{2}\right)^{1 / 2}+1282+350=10344$ soldiers, or 156 extra. In the Stewart $25 \%$ model their casualties while advancing are $39 \times 16.4409=641$. Their estimated threshold becomes $\left(4.5570(5330)^{2}\right)^{1 / 2}+641+350=12370$ soldiers, or 1871 extra.

\section{Scenario 4: Weaker Defenses}

In the Sears $25 \%$ model, the Confederates need only $\left(2.7737(7805-1950)^{2}\right)^{1 / 2}+1473+$ $350=11575$ soldiers, which is 1435 less than what they sent. With the Stewart $50 \%$ model, they need $\left(2.6714(5550-1400)^{2}\right)^{1 / 2}+3058+350=10191$ soldiers, or 309 less. With the Stewart $25 \%$ model, they need $\left(4.5570(5550-1400)^{2}\right)^{1 / 2}+1529+350=10739$ soldiers, or 239 extra.

\section{Scenario 5: Improved Barrage and Weakened Defense}

In the Sears $25 \%$ model, the Confederates have 172 cannon with coefficients of 0.2208 guns/gun and 2.1472 soldiers/gun. The Union has 6030 infantry, and loses 38 guns and 369 infantry in Phase I. The Confederates lose 1231 infantry during Phase II, and face 5661 Union soldiers in Phase III. The Confederates win with 6498 survivors. Their threshold is $\left(2.7737(7980-1950-369)^{2}\right)^{1 / 2}+1231+350=11007$ infantry, or 2023 less than sent.

In the Stewart $50 \%$ model, the Confederates have 150 cannon with coefficients of 0.2798 guns/gun and 2.7972 soldiers/gun. The Union has 4350 infantry, and loses 42 guns and 420 infantry in Phase I. The Confederates lose 2336 infantry during Phase II, to face 3930 Union soldiers in Phase III. Their threshold is $\left(2.6714(5750-1400-420)^{2}\right)^{1 / 2}+2336+350=9110$ infantry, or 1390 less. In the Stewart 25\% model, the Confederates lose 1168 infantry during

Phase II. Their threshold is $\left(4.5570(5750-1400-420)^{2}\right)^{1 / 2}+1168+350=9908$ infantry, or 592 less. 